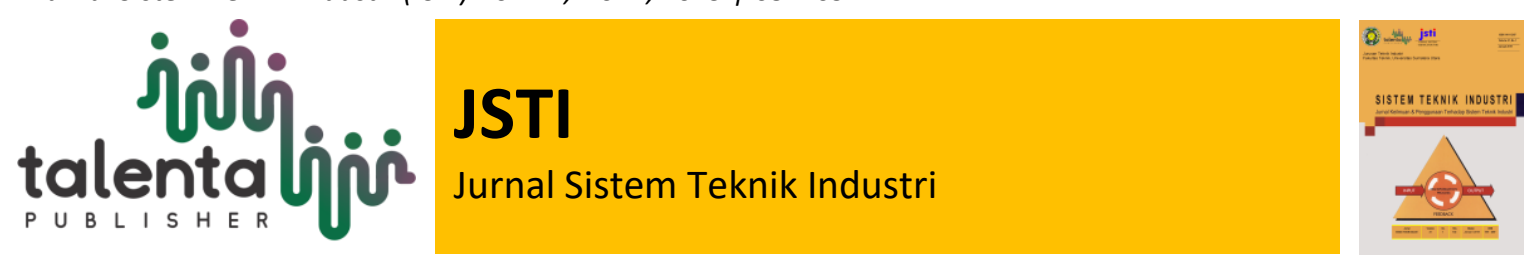

\title{
Perbaikan Produk Pakaian Pelindung Dingin Menggunakan Metode DFM Pada PT.XXX
}

\author{
Rosnani Ginting 1, Benedictus Vito Bayu Aji Indi 1 \\ ${ }^{I}$ Departemen Teknik Industri, Fakultas Teknik, Universitas Sumatera Utar, Medan, Indonesia
}

\begin{abstract}
Abstrak. Saat ini, persaingan di dunia industri sangat ketat. Untuk itu, pemenuhan kebutuhan produksi sesuai dengan permintaan merupakan hal yang penting. Meski demikian, PT. XXX membahas beberapa masalah dalam proses produksi produk. Masalah tersebut adalah proses yang rumit akibat produk yang cukup rumit dan bahan yang khusus. Jadi penelitian ini dilakukan perancangan produk yang lebih sederhana, komponen yang lebih sedikit dan waktu produksi yang lebih cepat menggunakan metode DFM dengan menggunakan Pemilihan Bahan dan Perbaikan pada Peta Operasi. Penerapan metode ini memberikan efisiensi desain sebesar $25,1 \%$ dan efisiensi biaya bahan sebesar $20 \%$.
\end{abstract}

Kata Kunci: DFM, Perbaikan Produk, Pakaian Pelindung Dingin

\begin{abstract}
At present, competition in the industrial world is very tight. For this reason, fulfilling production needs according to demand is important. However, PT. XXX discusses several problems in the product production process. This problem is a complicated process due to quite complex products and special materials. So this research is carried out simpler product design, fewer components and faster production time using the DFM method by using Material Selection and Improvement on the Operation Map. The application of this method provides a design efficiency of $25.1 \%$ and material cost efficiency of $20 \%$.
\end{abstract}

Keywords: DFM, Product Development, Cold Protective Clothing

Received 9 July 2019| Revised 26 July 2019| Accepted 26 July 2019

\section{Introduction}

PT. XXX merupakan perusahaan yang memproduksi produk pakaian tahan terhadap termal dingin dan sangat dingin. Pakaian ini biasa digunakan pada industri yang memiliki aktivitas pada kondisi dingin seperti pada perusahaan pengolah makanan berbasis daging yang memiliki cold storage. Pakaian yang dihasilkan PT. XXX harus mampu memberikan perlindungan terhadap pekerja yang menggunakannya agar pekerja tersebut bisa bekerja dengan baik dan tidak mengalami permasalahan yang membahayakan tubuh baik dalam jangka pendek maupun jangka panjang.

*Corresponding author at: Jl. Almamater Padang Bulan, Medan Baru, Medan City, North Sumatra 20222 
Perusahaan menghadapi beberapa masalah dalam proses produksi produk. Masalah tersebut adalah proses yang rumit akibat bentuk produk yang cukup rumit dan bahan yang khusus. Rancangan produk yang lebih sederhana, komponen yang lebih sedikit dan waktu produksi yang lebih cepat, merupakan alternatif solusi pemecahan masalah. Desain yang lebih mudah dirakit akan meningkatkan efisiensi penggunaan waktu yang berujung pada penurunan biaya produksi. Salah satu yang paling berpengaruh terhadap biaya total manufaktur adalah faktor desain.

Pengidentifikasian masalah pada penelitian ini dilakukan dengan menggunakan metode quality function deployment (QFD), yaitu suatu metodologi yang terkenal untuk desain dan pengembangan produk berorientasi pelanggan. Analisis masalah menggunakan QFD mendapatkan suatu matriks yang menghubungkan karakteristik teknis produk dan keinginan responden akan produk dan masalah yang dihadapai selama proses pengerjaan produk. House of quality (HOQ), sebuah alat dari QFD, membantu untuk menentukan batas-batas desain, menunjukkan hubungan antara kebutuhan responden dan matriks yang digunakan untuk memuaskan kebutuhan responden dan menggambarkan fokus tim perancang untuk menghasilkan produk yang berkualitas. Berikut ini merupakan QFD dari produk pakaian pelindung dingin. Berikut merupakan QFD fase 2 dari perancangan pakaian pelindung dingin.

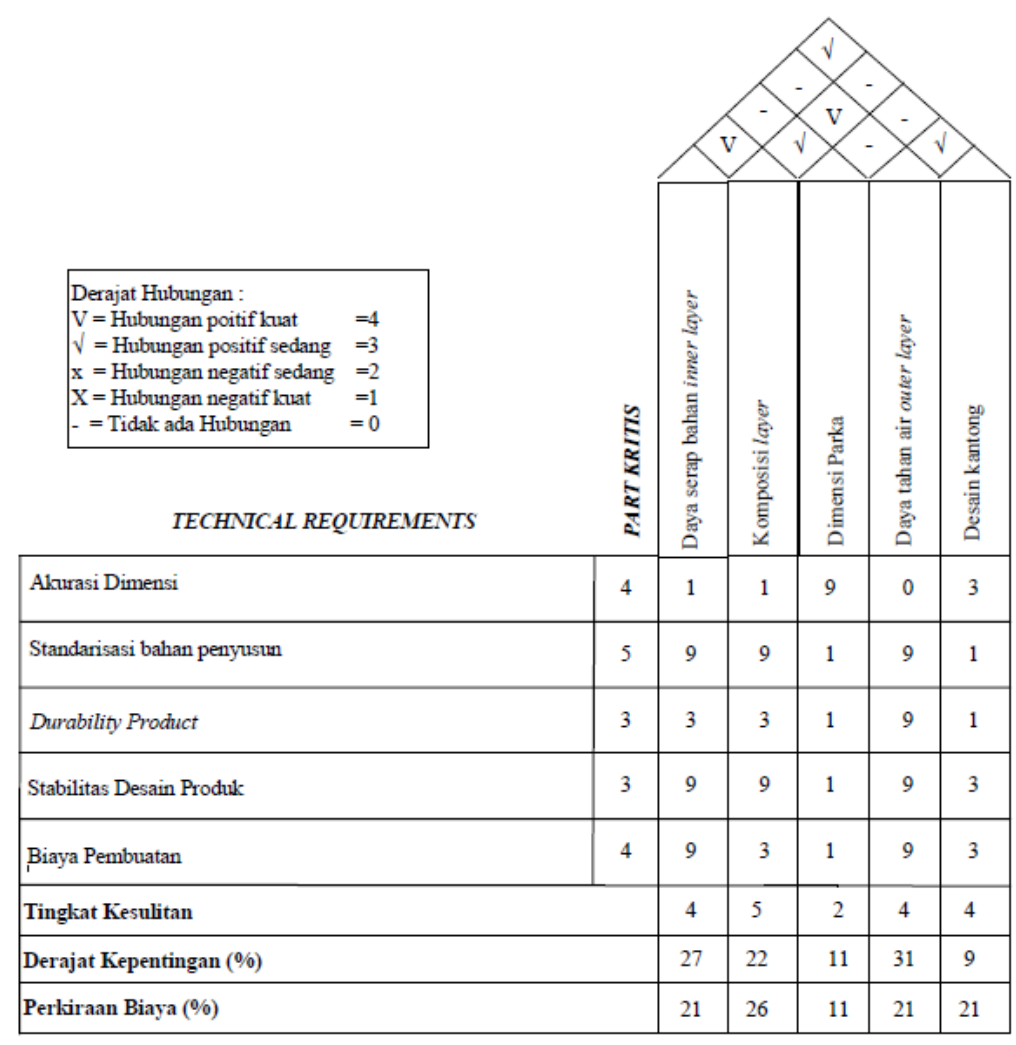

Figure 1 QFD Pakaian pelindung dingin

\section{Metode Penelitian}

Pada penelitian ini dilakukan jenis penelitian deskriptif dan bersarakan data primer yang sudah diperoleh pada penelitian sejenis sebelumnya. Ditinjau dari tingkat eksplanasi, penelitian ini 
termasuk penelitian deskriptif, karena penelitian ini akan memaparkan setiap variabel yang mempengaruhi masalah yang ada sekarang secara sistematis dan aktual berdasarkan data yang ada.

\subsection{Metode Pengolahan Data}

Langkah-langkah pengolahan data terbagi menjadi beberapa tahap yaitu Uji validitas dan reliabilitas, Pembuatan Matriks House of Quality, Penentuan Alternatif untuk Rancangan Produk Baru dengan Metode Value Engineering, Perancangan Produk dengan DFMA, Perbaikan Assembly Process Chart.

a. Perancangan Produk dengan DFMA dilakukang dengan langkah-langkah berikut:

(1) Membuat struktur produk dari desain awal produk.

(2) Evaluasi setiap part atau komponen penyusun produk dengan DFMA.

(3) Identifikasi part yang dapat dikembangkan, kombinasi dan dieliminasi.

(4) Membuat perbaikan urutan perakitan desain yang baru melalui assambly process chart. Dalam memperbaiki dan mengembangkan metode perakitan menjadi lebih baik dapat dilakukan dengan:

(a) Menghilangkan semua pekerjaan yang tidak perlu atau pekerjaan yang tidak mengandung nilai tambah

(b) Kombinasi Operasi atau elemen kegiatan, Mengubah urutan Operasi, dan

(5) Menyederhanakan Operasi melalui metode 5W dan $1 \mathrm{H}$

(6) Hitung Efisiensi Desain Perakitan Produk. Efisiensi desain perakitan menunjukkan perbandingan antara estimasi waktu perakitan produk redesign dengan waktu ideal perakitan produk sebelumnya. Waktu ideal didapatkan dengan mengasumsikan bahwa setiap komponen mudah untuk ditangani dan digabungkan.

(7) Menghitung Biaya Perakitan desain awal dan desain baru melalui estimasi upah tenaga kerja pada bagian perakitan.

(8) Hasil rancangan produk akhir dengan menggunakan metode DFMA. 


\section{Hasil dan Pembahasan}

\subsection{Perbaikan Produk dengan DFM}

Setelah data dikumpulkan pada pengumpulan data, kemudian data diolah sesuai dengan tahaptahap yang sesuai, yang dimulai dengan menentukan aktivitas dan desain produk awal. Berikut merupakan tabel komponen penyusun pakaian pelindung dingin.

Table 1 Komponen Penyusun Produk

\begin{tabular}{lll}
\hline Job & Atribut & Jenis Bahan \\
\hline 1 & Inner Layer Cloth & Kain Sutra \\
2 & Outer Layer Cloth & Kain Nylon \\
3 & Shoulder Upper Cloth & Kain Nylon \\
4 & Front Upper Cloth & Kain Nylon \\
5 & Sleeve Upper Cloth & Kain Nylon \\
6 & Waist Lower Cloth & Kain Nylon \\
7 & Outsteam Lower Cloth & Kain Nylon \\
8 & Kantung Baju & Kain Sutra \\
8 & Penyambung Bagian & Benang Sutra \\
9 & Penutupan Baju & Kancing Plastik \\
\hline
\end{tabular}

Kemudian dapat dilakukan proses perakitan produk baju sesuai dengan aktivitas berikut ini.

Table 2 Elemen Kegiatan Pembuatan Produk

\begin{tabular}{ll}
\hline No & \multicolumn{1}{c}{ Elemen Kegiatan } \\
\hline 1 & Mengukur dan memotong kain Sutra untuk Inner Layer Cloth \\
2 & Mengukur dan memotong kain Nylon untuk Outer Layer Cloth \\
3 & Mengukur dan memotong kain Nylon untuk Shoulder Upper Cloth \\
4 & Mengukur dan memotong kain Nylon untuk Front Upper Cloth \\
5 & Mengukur dan memotong kain Nylon untuk Sleeve Upper Cloth \\
6 & Mengukur dan memotong kain Nylon untuk Waist Lower Cloth \\
7 & Mengukur dan memotong kain Nylon untuk Outsteam Lower Cloth \\
8 & Melubangi Outsteam Lower Cloth untuk bagian kantung \\
9 & Mengukur dan memotong kain Sutra untuk Bagian Kantung \\
10 & Menyambung bagian kantung menjadi satu kesatuan \\
11 & Menyambung set kantung dengan Outsteam Lower Cloth \\
12 & Menyambung Inner Layer Cloth dengan Outer Layer Cloth menjadi Bagian Utama \\
13 & Menyambung Shoulder Upper Cloth dengan bagian utama \\
14 & Menyambung Front Upper Cloth degan bagian utama \\
15 & Menyambung Sleeve Upper Cloth degan bagian utama \\
16 & Menyambung Waist Lower Cloth dengan bagian utama \\
17 & Menyambung Outsteam Lower Cloth dengan bagian utama \\
18 & Memasang kancing pada bagian depan pakaian \\
\hline
\end{tabular}

Berdasarkan Elemen kegiatan yang ada pada tabel tersebut dapat diidentifikasi komponen yang memiliki permasalahan sehingga dapat dilakukan perbaikan. Berikut merupakan hasil identifikasi permasalahan pada komponen penyusun produk. 
Table 3 Identifikasi Komponen Penyusun Produk

\begin{tabular}{|c|c|c|c|}
\hline No. & Nama Komponen & Fungsi Komponen & Masalah \\
\hline 1. & Kantung Baju & $\begin{array}{l}\text { Sebagai } r \text { tempat } \\
\text { penyimpanan benda pada } \\
\text { baju }\end{array}$ & $\begin{array}{l}\text { Menambah waktu perakitan } \\
\text { yang lama }\end{array}$ \\
\hline 2. & Inner Layer Cloth & $\begin{array}{l}\text { Sebagai lapisan dalam pada } \\
\text { pakaian }\end{array}$ & $\begin{array}{l}\text { Menggunakan bahan yang } \\
\text { cukup mahal }\end{array}$ \\
\hline
\end{tabular}

Tabel diatas merupakan permasalahan yang dihadapi pada proses produksi. Untuk mengatasi permasalahan tersebut, dapat diberikan solusi perbaikan untuk setiap permaslahan sebagai berikut.

Table 4 Solusi Perbaikan Tiap komponen

\begin{tabular}{cccc}
\hline No. $\begin{array}{c}\text { Nama } \\
\text { komponen }\end{array}$ & $\begin{array}{c}\text { Fungsi } \\
\text { Komponen }\end{array}$ & Solusi Perbaikan \\
\hline 1. & Kantung Baju & $\begin{array}{c}\text { Sebagai tempat } \\
\text { penyimpanan benda } \\
\text { pada baju }\end{array}$ & $\begin{array}{c}\text { dilakukan perbaikan terhadap } \\
\text { rancangan } \\
\text { membuat desain kantung yang baru } \\
\text { kaitu kantung satu lapis pada bagian } \\
\text { luar pakaian } \\
\text { Menggunakan bahan yang lebih }\end{array}$ \\
2. & Cloth & Layer & $\begin{array}{c}\text { Sebagai lapisan } \\
\text { dalam pada pakaian namun tetap menjalankan } \\
\text { fungsi yang semestinya }\end{array}$ \\
\hline
\end{tabular}

Perbaikan dengan Metode DFMA dilakukan dengan memperbaiki Struktur Produkserta APC dengan menggunakan metode perbaikan pada peta proses. Perbaikan tersebut dilakukan dengan mempertimbangkan solusi yang diperoleh. langkah-langkah perbaikan pada Struktur Produk dan APC menggunakan langkah perbaikan pada peta proses, seperti eliminasi kegiatan yang tidak diperlukan, menggabungkan kegiatan sejenis, maupun mengubah metode. Berikut merupakan hasil struktur produk dan APC yang telah mengalami perbaikan.

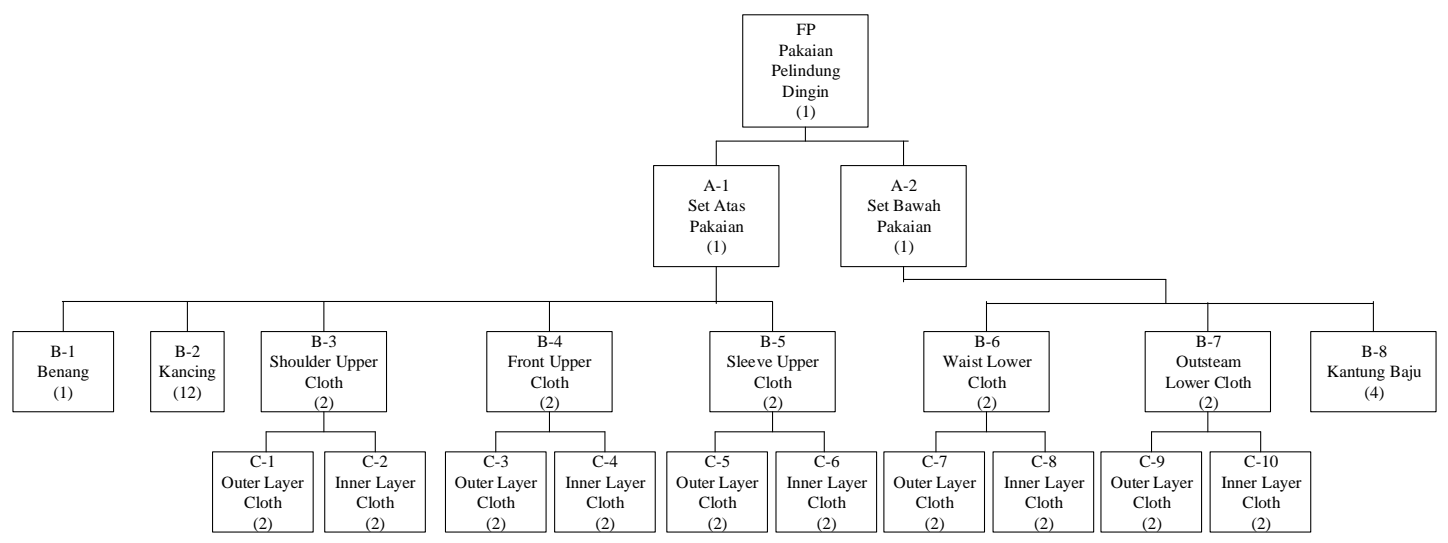

Figure 2 Hasil Perbaikan pada Struktur Produk 


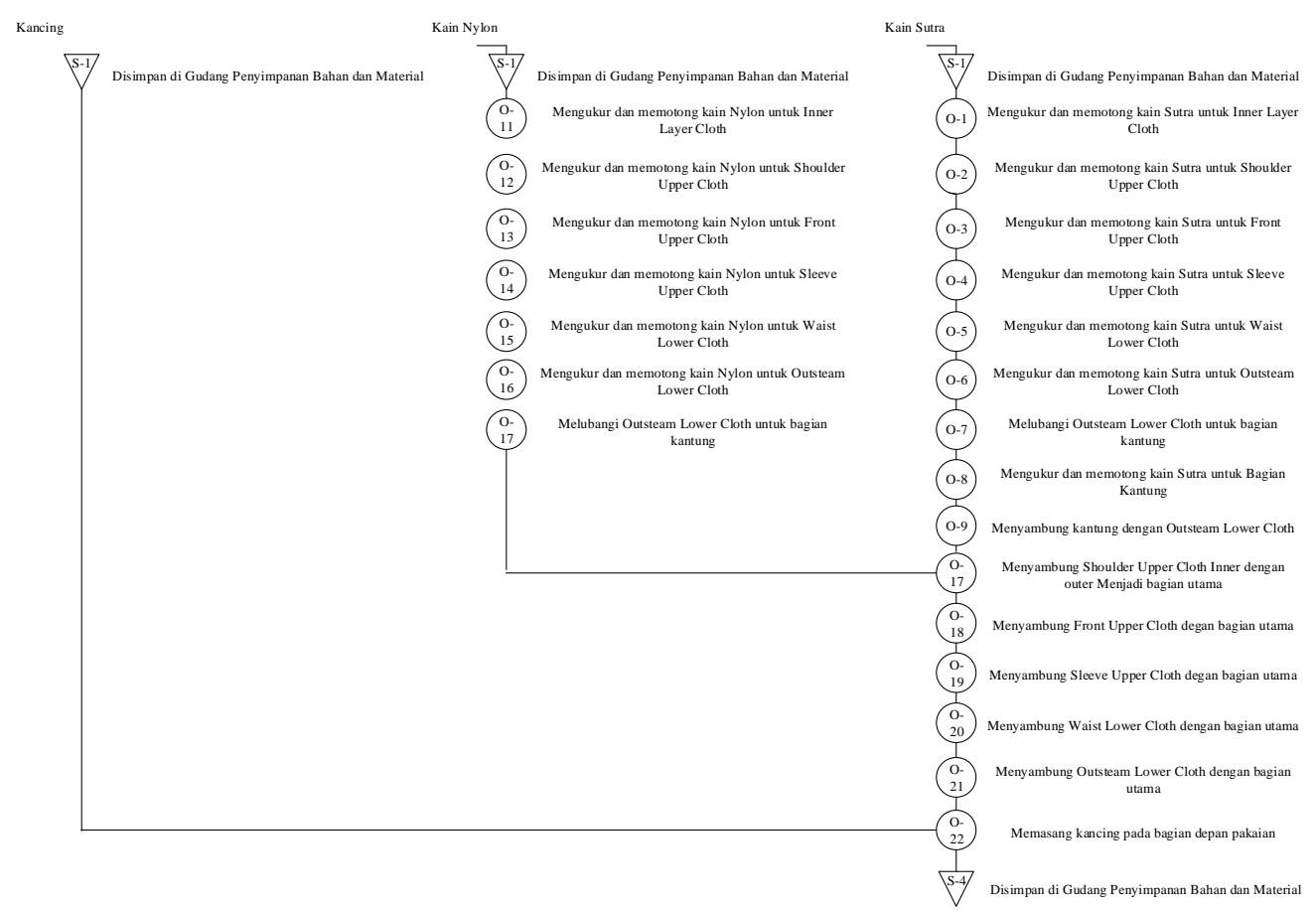

Figure 3 Hasil Perbaikan pada APC

\subsection{Efisiensi Desain dan Jumlah Produk Standar}

Efisiensi desain perakitan menggambarkan perbandingan antara estimasi waktu perakitan produk redesign dengan waktu ideal perakitan produk sebelumnya. Waktu ideal didapatkan dengan mengasumsikan bahwa setiap komponen mudah untuk ditangani dan digabungkan.

Setelah dilakukan perhitungan, diperoleh hasil efisiensi terhadap proses produksi, berikut merupakan tabel efisiensi desain setelah tahap DFMA.

Table 5 Efisiensi Desain Setelah Tahap DFMA

\begin{tabular}{lllc}
\hline No & Design & Eff. Design & $\begin{array}{c}\text { Jumlah Produk } \\
\text { yang Dihasilkan }\end{array}$ \\
\hline 1 & Desain Awal (Original Design) & $24,21 \%$ & 59 Unit \\
2 & Desain Perbaikan (DFMA) & $25,1 \%$ & 62 Unit \\
\hline
\end{tabular}

Sedangkan untuk perhitungan efisiensi biaya yaitu penggantian material memberikan efisiensi biaya sebesar $20 \%$.

\section{Kesimpulan}

Berdasarkan pembahasan, kesimpulan yang diperoleh dari penelitian ini yaitu:

a. Karakteristik teknis yang menjadi prioritas perbaikan berdasarkan house of quality QFD yaitu Tahan Air Outer Layer, Daya Serap Bahan Inner Layer, serta Komposisi Layer.

b. Perbaikan rancangan produk dengan metode Design for Manufacture and Assembly menghasilkan rancangan produk pakaian pelindung dingin yang mengalami penghematan waktu perakitan sebesar 0,24 menit/unit produk, peningkatan efisiensi desain sebesar 0,89\%, 
peningkatan jumlah produksi sebesar 3 unit/hari dan penghematan biaya perakitan sebesar Rp 1.309,61/unit produk pakaian pelindung dingin, juga terjadi penghematan biaya material sebesar Rp 96.000 per unit atau sekitar 20\%.

\section{REFERENSI}

[1] Farag, Mahmoud M. 2013. Materials and Process Selection for Engineering Design. USA: CRC Press.

[2] Klamecki, Barney E. 2003. Materials and Process in Manufacturing. John Wiley \& Sons, Inc.

[3] Poli, Corrado. 2001. Design for Manufacturing: A Structured Approach. Butterworth: Elsevier Science\&Technology Books.

[4] Sutalaksana, Iftikar Z. 2005. Teknik Tata Cara Kerja. Bandung: ITB. 